\title{
Validation of an enzyme-linked immunosorbent assay developed for measuring cortisol concentration in human saliva and serum for its applicability to analyze cortisol in pig saliva
}

\author{
Ola Thomsson ${ }^{1 *}$, Bodil Ström-Holst ${ }^{2}$, Ylva Sjunnesson $^{1}$ and Ann-Sofi Bergqvist ${ }^{1}$
}

\begin{abstract}
Background: The purpose of this study was to validate a commercially available enzyme-linked immunosorbent assay (ELISA) developed for measuring free cortisol in human saliva and total cortisol concentration in diluted human serum, for its applicability in measuring cortisol concentration in pig saliva. Collection of saliva is less stressful than e.g. blood sampling, and is a non-invasive method.

Findings: Saliva was collected by allowing sows to chew on cotton swabs held by forceps. Thereafter, the swabs were centrifuged to retrieve the saliva. The ELISA was performed according to instructions provided by the manufacturer. To validate the ELISA, determination of the intra-assay coefficient of variation (CV), inter-assay CV, recovery, linearity and parallelism was performed. The intra-assay CV was below 10\% and inter-assay CV below 15\% for samples of high, medium and low cortisol concentrations. The mean recovery was $117 \%$ and the linearity and parallelism showed an $r^{2}$-value of 0.994 and 0.993 , respectively. For biological assessment of induced social stress, two saliva samples were collected in the morning from 6 primiparous and 21 multiparous sows. One sample was collected when the sows were individually housed in a farrowing pen and a second sample was collected when the sows were group housed. The primiparous sows had a significant higher cortisol concentration compared to the multiparous sows when group housed.
\end{abstract}

Conclusion: The results obtained in this validation study indicate that the ELISA is suitable for measuring cortisol concentration in porcine saliva.

Keywords: Stress, Porcine, Sow, Group housing, Multiparous, Primiparous

\section{Findings}

Cortisol is a stress hormone produced by the adrenal glands and is commonly measured to assess stress in a variety of animals, including pigs. Cortisol can be measured in plasma or serum [1,2]. However, blood sampling requires either restraint of the pig during sampling, thus being exposed to stress, or surgical insertion of a catheter, which is difficult in large-scale studies or studies conducted in less controlled housing environments [3]. Sampling of saliva, urine and faeces is non-invasive compared

\section{* Correspondence: ola.thomsson@slu.se}

'Division of Reproduction, Department of Clinical Sciences, Swedish University of Agricultural Sciences, SLU, Box 7054, SE-750 07 Uppsala, Sweden

Full list of author information is available at the end of the article to blood sampling. Cortisol metabolites can be measured in urine, but to obtain accurate results urine concentration must be taken into account. Furthermore, urine sampling can be time-consuming as an observer must be present to collect urine when the sow urinates [4]. On the other hand, faeces is easy to collect. A drawback can be that peaks of cortisol are difficult to detect, since the obtained concentration will be a reflection of the cortisol production over time [5]. Saliva is easy to collect and salivary cortisol reflects the biologically active, unbound cortisol in plasma [6,7]. Therefore, collection of saliva is a suitable sampling technique in less controlled environments such as when pigs are mixed and group housed.
C Biomed Central

(c) 2014 Thomsson et al.; licensee BioMed Central Ltd. This is an Open Access article distributed under the terms of the Creative Commons Attribution License (http://creativecommons.org/licenses/by/2.0), which permits unrestricted use, distribution, and reproduction in any medium, provided the original work is properly credited. The Creative Commons Public Domain Dedication waiver (http://creativecommons.org/publicdomain/zero/1.0/) applies to the data made available in this article, unless otherwise stated. 
Group-housing of sows has been reported to be stressful due the establishment of a new order of rank, usually by more or less violent encounters [8]. It has also been reported that mixing of pigs has an effect on cortisol levels as it is considered a result of social stress [9-11]. Further young sows experience more social stress when housed together with older sows and young sows have a higher cortisol level compared to the older sows [12]. An increase in cortisol levels could also be linked to a reduced on-farm animal welfare [13]. In Swedish organic and conventional piglet production, mixing and group-housing of sows has been practiced since the 1980s and it is also becoming more common within the European Union. Thus, to conduct stress research easily on mixing and group-housing of sows, a combination of saliva collection and a simple analytic method would be useful.

There are several methods for analyzing cortisol in saliva $[1,2,14,15]$, the majority of which being immunoassays. Enzyme-linked immunosorbent assays (ELISA) are widely used in laboratories today. To the authors knowledge there is no commercially available ELISA that has been validated for quantifying cortisol in pig saliva. The aim of the present study was to validate a commercially available ELISA developed for measuring free cortisol in human saliva and total cortisol concentration in diluted human serum, for its applicability in measuring cortisol concentration in pig saliva.

Validation was made both methodologically and biologically. Saliva from five multiparous and one primiparous sow were used for the methodological validation. One multiparous sow was only used for investigation of linearity. The primiparous sow and two multiparous sows were used for recovery studies. One of these multiparous sows, together with two other sows, was also used for calculations of $\mathrm{CV}$, and for the biological validation. A total of 27 sows, 21 multiparous and six primiparous sows, were used for the biological validation. All sows included in this study were healthy pure-bred Yorkshire sows. The study was approved by the Uppsala Animal Ethical Committee (C154/11).

Mixing and group housing of 27 sows was used as a model for social stress as it is known to induce stress [9-11]. One morning saliva sample was collected when the sows were still housed in individual farrowing pens and another morning sample was collected when the sows had been group housed for $12 \mathrm{~h}$. The group size varied between 5 and 8 sows.

Saliva was collected using a Sarstedt Salivette ${ }^{\circledR}$ for saliva collection (ref. 51.1534, Sarstedt, Nümbrecht, Germany). The cotton swab was held with forceps and the sow was allowed to chew on the cotton swab until it was soaked. The swab was centrifuged at $2400 \times g$ in room temperature, for 2 min using a Hettich Centrifuge
EBA 20 (Andreas Hettich Group, Ltd., Tuttlingen, Germany), within 30 minutes after collection. The recovered saliva was aliqouted and stored at $-20^{\circ} \mathrm{C}$ until analyzed.

A competitive ELISA (Cortisol ELISA, IBL International, Hamburg, Germany) developed for quantitative analysis of free cortisol in human saliva and the total cortisol concentration in diluted human serum was used. According to the manufacturer the limit of detection was $0.005 \mu \mathrm{g} / \mathrm{dl}$. The assay was performed according to the instructions provided by the manufacturer. The saliva samples were thawed and centrifuged at $3000 \times g$ at room temperature for $10 \mathrm{~min}$ using Hereaus Fresco 17 centrifuge (ThermoScientific, West Sussex, United Kingdom). The plate was shaken for $2 \mathrm{~h}$ using an orbital shaker (Flow Laboratories DSG Titertek, Pforzheim, Germany). For the washing procedure an automatic plate washer Hydroflex Tecan (Tecan Group, Ltd., Männerdorf, Switzerland) was utilized. Optical density was measured by a Multiscan EX (Thermo Labsystems, Vantaa, Finland). The results were calculated using four-parameter-logistic as recommended by the manufacturer.

To calculate recovery, saliva samples from sow A, B and $C, 80 \mu$ l were mixed with accompanying standards in ratio of 1:1 and pipetted into wells in triplicates. Undiluted samples were analysed to determine the cortisol concentration of the three samples. The concentration was rounded to two decimal places. Recovery was calculated using the formula: (detected concentration/expected concentration) *100. Expected concentration was calculated using the formula: (concentration of undiluted sample + concentration of the added standard) *0.5

Samples of high, medium and low concentration in two replicates were used to calculated intra-assay and inter-assay coefficients of variation according to Jaedicke et al. [16]. Acceptable range was determined for intraassay CV to $10 \%$ and inter-assay CV to $15 \%$ [17].

To determine linearity and parallelism, a sample of known high concentration of cortisol and the high concentration accompanying standard were diluted 1:2, 1:4 $1: 8,1: 16,1: 32$ with zero standard and pipetted in to wells in triplicates.

The differences in cortisol concentrations between primiparous and multiparous sows in samples collected before and after group housing were compared. A Shapiro-Wilk test showed that the cortisol concentrations were not normally distributed and the analysis was therefore conducted using the Wilcoxon rank-sum test. A $P$-value $<0.05$ was considered significant.

The recovery is presented in Table 1 . The mean recovery for sows A, B and C were 110\%, 89\% and 154\%, respectively. The overall recovery was $118 \%$. The results of the linearity and parallelism are presented in Figure 1, whereas Table 2 shows the intra-assay and inter-assay CVs. Intra-assay $\mathrm{CV}$ 
Table 1 Recovery rate in three samples from 3 sows (A, B and C) with different cortisol concentration mixed with accompanying standards

\begin{tabular}{|c|c|c|c|c|c|c|c|c|c|}
\hline \multirow{2}{*}{$\begin{array}{l}\text { Added } \\
\text { concentration }{ }^{1} \\
\mu \mathrm{g} / \mathrm{dl}\end{array}$} & \multicolumn{3}{|c|}{ Sow A $(0.58 \mu \mathrm{g} / \mathrm{dl})^{2}$} & \multicolumn{3}{|c|}{ Sow $B(0.42 \mu \mathrm{g} / \mathrm{dl})^{2}$} & \multicolumn{3}{|c|}{ Sow $C(0.54 \mu \mathrm{g} / \mathrm{dl})^{2}$} \\
\hline & Expected conc. & Detected conc. & Recovery \% & Expected conc. & Detected conc. & Recovery \% & Expected conc. & Detected conc. & Recovery \% \\
\hline 0.03 & 0.31 & 0.37 & 119 & 0.23 & 0.21 & 91 & 0.29 & 0.42 & 145 \\
\hline 0.06 & 0.32 & 0.34 & 106 & 0.24 & 0.19 & 79 & 0.30 & 0.48 & 160 \\
\hline 0.20 & 0.39 & 0.42 & 108 & 0.31 & 0.24 & 77 & 0.56 & 0.56 & 151 \\
\hline 0.60 & 0.59 & 0.57 & 97 & 0.51 & 0.49 & 96 & 0.57 & 0.91 & 160 \\
\hline 1.50 & 1.04 & 1.31 & 126 & 0.96 & 0.90 & 94 & 1.02 & 1.78 & 175 \\
\hline 4.00 & 2.29 & 2.38 & 104 & 2.21 & 2.08 & 94 & 2.27 & 3.00 & 132 \\
\hline
\end{tabular}

${ }^{1}$ Concentration added in 1:1 ratio.

${ }^{2}$ The undiluted cortisol concentration of the sample. 


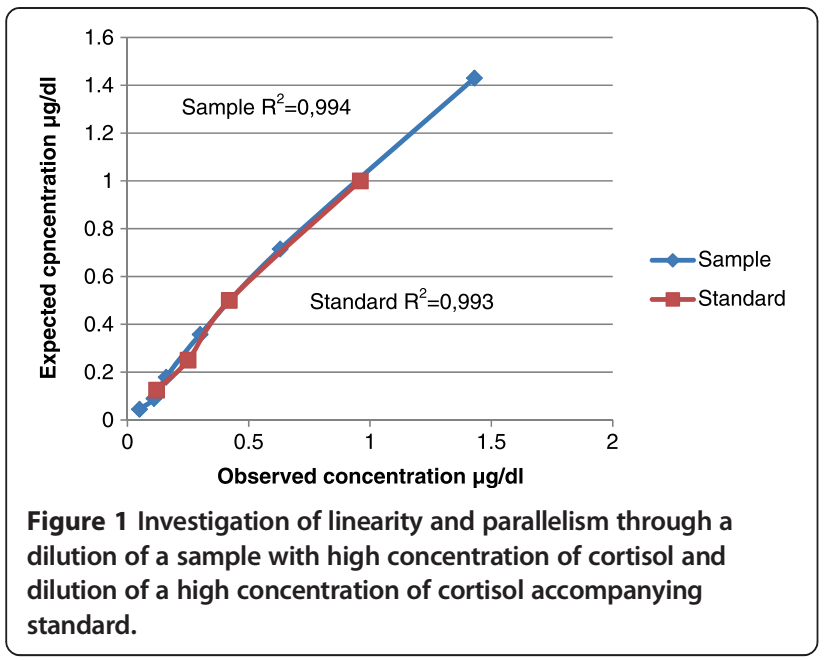

ranged from $0.9 \%$ to $4.8 \%$ and the inter-assay $\mathrm{CV}$ ranged from $5.9 \%$ to $14.8 \%$.

The concentrations of cortisol did not differ significantly $(P=0.81)$ in morning samples collected from single housed multiparous (median $0.47 \mu \mathrm{g} / \mathrm{dl}$, range $0.14-2.53 \mu \mathrm{g} / \mathrm{dl}$ ) compared to single housed primiparous sows (median $0.66 \mu \mathrm{g} / \mathrm{dl}$, range $0.10-1.17 \mu \mathrm{g} / \mathrm{dl})$. However the concentration of cortisol did differ significantly $(P=0.03)$ in morning samples collected during group housing between multiparous and primiparous sows, with a higher concentrations for the primiparous sows. The median for the primiparous sows was $0.44 \mu \mathrm{g} / \mathrm{dl}$ (range $0.50-1.23 \mu \mathrm{g} / \mathrm{dl}$ ) and for multiparous sows the median was $0.31 \mu \mathrm{g} / \mathrm{dl}(0.08-0.60 \mu \mathrm{g} / \mathrm{dl})$ for the samples after group housing.

In this study the overall recovery reported was lower than in other validation studies of cortisol measured in saliva with different immunoassays $[14,18]$. However it was still within acceptable range of $80 \%-120 \%$ [16]. The higher overall recovery was mainly due to the overrecovery of sow $\mathrm{C}$. The intra-assay $\mathrm{CV}$ was below $10 \%$ and the inter-assay $\mathrm{CV}$ was below $15 \%$ for all sample concentrations which is acceptable [17]. The $r^{2}$ - value was close to unity for both the diluted sample and the diluted high standard and, together with an acceptable recovery, indicates a high accuracy [14]. Together these results indicate that the ELISA is suitable for analyzing cortisol concentrations in pig saliva.

Table 2 Intra-assay and inter-assay coefficients of variation of samples with high, medium or low cortisol concentrations

\begin{tabular}{|c|c|c|c|c|c|c|}
\hline \multirow{2}{*}{$\begin{array}{l}\text { Sample } \\
\text { concentration }\end{array}$} & \multicolumn{3}{|c|}{ Intra-assay CV } & \multicolumn{3}{|c|}{ Inter-assay CV } \\
\hline & Mean $\mu \mathrm{g} / \mathrm{dl}$ & SD & CV \% & Mean $\mu \mathrm{g} / \mathrm{dl}$ & SD & CV \% \\
\hline High & 3.23 & 0.16 & 5.0 & 3.42 & 0.20 & 5.9 \\
\hline Medium & 2.25 & 0.04 & 1.8 & 1.96 & 0.29 & 14.8 \\
\hline Low & 0.55 & 0.01 & 1.8 & 0.48 & 0.06 & 13.0 \\
\hline
\end{tabular}

In the biological validation of the present study the cortisol concentrations differed significantly between multiparous sows and primiparous sows when group housed. The same difference with higher cortisol concentrations for primiparous sows compared to multiparous sows at group housing has previously been reported as a result of socially induced stress $[12,19]$. The result obtained from the mixing of multiparous sows and primiparous sows in this study is supported by results in previous studies. The cortisol levels also appeared to be lower in group housed compared to individually housed sows regardless of parity, corresponding to previous studies [20,21].

In conclusion the results of this validation imply that the cortisol ELISA provided by IBL International is suited for analyzing cortisol concentrations in pig saliva.

\section{Competing interests}

The authors declare that they no competing interests.

\section{Authors' contributions}

OT was responsible for drafting the manuscript and carried out the ELISA. OT,YS and ASB performed the collection of the saliva. OT, YS, ASB and BSH participated in the design of the validation. ASB, YS, BSH have revised the manuscript. All authors have read and approved the final manuscript.

\section{Acknowledgements}

We want to thank Marta Kot and Anna Svensson for advice through the validation process. The authors are also thankful to Jane Morrell for English revision of the manuscript.

\section{Author details}

${ }^{1}$ Division of Reproduction, Department of Clinical Sciences, Swedish University of Agricultural Sciences, SLU, Box 7054, SE-750 07 Uppsala, Sweden. 'Division of Diagnostics and Large Animal Clinical Sciences, Department of Clinical Sciences, Swedish University of Agricultural Sciences, SLU, Box 7054SE-750 07 Uppsala, Sweden.

Received: 1 November 2013 Accepted: 27 August 2014

Published: 6 September 2014

\section{References}

1. Colson V, Martin E, Orgeur P, Prunier A: Influence of housing and social changes on growth, behaviour and cortisol in piglets at weaning. Physiol Behav 2012, 107:59-64.

2. Brandt $Y$, Lang A, Rodriguez-Martinez $H$, Madej A, Einarsson S: Impact of ACTH during oestrus on the ultrastructure of the spermatozoa and their environment in the tubal reservoir of the postovulatory sow. Anim Reprod Sci 2006, 93:231-245.

3. Cook NJ, Schaefer AL, Lepage P, Jones SDM: Radioimmunoassay for cortisol in pig saliva and serum. J Agric Food Chem 1997, 45:395-399.

4. Pol F, Courboulay V, Cotte J-P, Martrenchar A, Hay M, Mormède P: Urinary cortisol as an additional tool to assess the welfare of pregnant sows kept in two types of housing. Vet Res 2002, 33:13-22.

5. Möstl E, Palme R: Hormones as indicators of stress. Domest Anim Endocrinol 2002, 23:67-74.

6. Brandt $\mathrm{Y}$, Einarsson S, Ljung A, Lundeheim N, Rodríguez-Martínez $\mathrm{H}$, Madej A: Effects of continuous elevated cortisol concentrations during oestrus on concentrations and patterns of progesterone, oestradiol and $\mathrm{LH}$ in the sow. Anim Reprod Sci 2009, 110:172-185.

7. Kerlik J, Penesova A, Vlcek M, Imrich R, Vogeser M, Radikova Z: Comparison of salivary cortisol and calculated free plasma cortisol during low-dose ACTH test in healthy subjects. Clin Biochem 2010, 43:764-767.

8. Coutellier L, Arnould C, Boissy A, Orgeur P, Prunier A, Veissier I, MeunierSalaün M-C: Pig's responses to repeated social regrouping and relocation during the growing-finishing period. Appl Anim Behav Sci 2007, 105:102-114. 
9. Parrott RF, Misson BH: Changes in pig salivary cortisol in response to transport simulation, food and water deprivation, and mixing. Br Vet $J$ 1989, 145:501-505.

10. Soede NM, van Sleuwen MJW, Molenaar R, Rietveld FW, Schouten WPG, Hazeleger W, Kemp B: Influence of repeated regrouping on reproduction in gilts. Anim Reprod Sci 2006, 96:133-145.

11. Ekkel ED, van Doorn CE, Hessing MJ, Tielen MJ: The Specific-Stress-Free housing system has positive effects on productivity, health, and welfare of pigs. J Anim Sci 1995, 73:1544-1551.

12. $L i ~ Y Z$, Wang $L H$, Johnston $L$ : Sorting by parity to reduce aggression toward first-parity sows in group-gestation housing systems. J Anim Sci 2012, 90:4514-4522.

13. Smulders D, Verbeke G, Mormede P, Geers R: Validation of a behavioral observation tool to assess pig welfare. Physiol Behav 2006, 89:438-447.

14. Escribano D, Fuentes-Rubio M, Ceron JJ: Validation of an automated chemiluminescent immunoassay for salivary cortisol measurements in pigs. J Vet Diagn Invest 2012, 24:918-923.

15. Fuentes M, Tecles F, Gutiérrez A, Otal J, Martínez-Subiela S, Cerón JJ: Validation of an automated method for Salivary Alpha-Amylase measurements in Pigs (Sus Scrofa Domesticus) and its application as a stress biomarker. J Vet Diagn Invest 2011, 23:282-287.

16. Jaedicke KM, Taylor JJ, Preshaw PM: Validation and quality control of ELISAs for the use with human saliva samples. I Immunol Methods 2012, 377:62-65.

17. Guidance for industry- bioanalytical method validation. http://www.fda. gov/downloads/Drugs/GuidanceComplianceRegulatorylnformation/ Guidances/ucm070107.pdf.

18. Ekkel ED, Dieleman SJ, Schouten WGP, Portela A, Cornélissen G, Tielen MJM, Halberg F: The circadian rhythm of cortisol in the saliva of young pigs. Physiol Behav 1996, 60:985-989.

19. Strawford ML, Li YZ, Gonyou HW: The effect of management strategies and parity on the behaviour and physiology of gestating sows housed in an electronic sow feeding system. Can J Anim Sci 2008, 88:559-567.

20. De Leeuw J, Ekkel E: Effects of feeding level and the presence of a foraging substrate on the behaviour and stress physiological response of individually housed gilts. Appl Anim Behav Sci 2004, 86:15-25.

21. Merlot E, Vincent A, Thomas F, Meunier-Salaün M-C, Damon M, Robert F, Dourmad J-Y, Lebret B, Prunier A: Health and immune traits of Basque and Large White pigs housed in a conventional or enriched environment. Animal Int J Anim Biosci 2012, 6:1290-1299.

doi:10.1186/s13028-014-0055-1

Cite this article as: Thomsson et al:: Validation of an enzyme-linked immunosorbent assay developed for measuring cortisol concentration in human saliva and serum for its applicability to analyze cortisol in pig saliva. Acta Veterinaria Scandinavica 2014 56:55.

\section{Submit your next manuscript to BioMed Central and take full advantage of:}

- Convenient online submission

- Thorough peer review

- No space constraints or color figure charges

- Immediate publication on acceptance

- Inclusion in PubMed, CAS, Scopus and Google Scholar

- Research which is freely available for redistribution 